Airport, safety at sea, radio and allied techniques on British Railways, and with the present and future of colour television. Other articles provide a review of the present position of transistors, and of the significance of automatic computation in research, industry and commerce. There are also interesting sections of this issue dealing with "Electronics in Action" and "New Equipment and Components". The presentation and layout of the journal, with its excellent photographs, diagrams and explanatory charts, are of a high standard, and are a credit to the publishers, Heywood and Co., Ltd., Drury House, Russell Street, London, W.C.1 ; it is only available by annual subscription of $£ 110 s$. for twelve issues, post paid $(6$ dollars in the United States and Canada).

\section{Agriculture: Diamond Jubilee Number}

Starting as a quarterly publication in 1894, Agriculture, the now monthly journal of the Ministry of Agriculture, has maintained an unbroken and increasingly useful service to the farming community of England and Wales. Both the scope and influence of the journal have widened considerably since it first began, and it is now regarded as an authoritative source of scientific and practical information for farmers, market gardeners and fruit growers alike. The journal celebrated its diamond jubilee last September and the number for that occasion (London : H.M.S.O. 1s. net) contains various articles of interest, each contributed by specialists in the subject. The underlying theme is the progress made during the past sixty years in such fields as plant and animal nutrition and breeding, crop protection, horticulture and mechanization, and it is hard to realize how comparatively recent are many of the accepted practices of to-day. Other articles describe the changes that have taken place in Welsh agriculture, landownership and rural social conditions, while contributions of a more general nature deal with agricultural research, elimate and the part played by agricultural societies, press and radio. Many readers will enjoy the personal touch provided by "I remember", a miscellany of recollections by some members of the older generation, and the beautiful illustrations depicting the varied nature of the English farming countryside.

\section{Phyto-Sanitary Convention for Africa South of the Sahara}

THE member governments of the Commission for Technical Co-operation in Africa South of the Sahara (Belgium, France, the Federation of Rhodesia and Nyasaland, Portugal, the Union of South Africa and the United Kingdom) have signed in London $\mathbf{a}$ Phyto-Sanitary Convention for Africa South of the Sahara. The objects of the Convention are to prevent the introduction of plant pests and diseases and other enemies of plants into any part of Africa south of the Sahara, to eradicate or control any that are at present in the area and to prevent their spread. It has established an Inter-African Phyto-Sanitary Commission on which each of the participating governments will be represented, and each participating government, as may be considered necessary by the Commission, will be required to exercise control of plant importations, and to apply measures of quarantine certification and inspection. It will also take any necessary action to deal effectively with diseases, insects, pests and other enemies of plants which have become or are likely to become a serious danger within the area, and to prohibit the importation of any plant material, seed or packing material which the Commission considers should be refused admittance into the area. The Commission is to have a scientific secretary and there is to be set up in London a Permanent Committee of Information consisting of the directors of the Commonwealth Institutes of Entomology and Mycology and the Scientific Secretary. This Committee will act as an intermediary between the two Commonwealth Institutes concerned and the African Phyto-Sanitary Commission for the transmission of relevant information about diseases, etc. The Convention will come into force as soon as it has been ratified.

\section{Commonwealth Oceanographic Conference}

A Commonwealth Oceanographic Conference is to be held in the National Institute of Oceanography at Wormley, near Godalming, Surrey, during October 18-22. Australia, Now Zealand, Canada, India and Pakistan are sending representatives, and observers will be attending on behalf of South Africa and Ceylon. Delegates from the United Kingdom will include representatives of the many government departments and scientific bodies interested in oceanographic research. The Conference has been arranged on the initiative of the National Oceanographic Council, to consider the possibility of closer co-operation in oceanographic research throughout the British Commonwealth. The need for such co-operation has become more pressing in recent years, as the tendency in oceanography has been to devote more and more effort to theoretical studies in an attempt to understand the fundamental physical and biological processes which are responsible for and cause variations in the properties of the waters, rather than to collect and analyse data concerning the water movements, temperature, chemical properties, distribution of marine life, etc., formerly the main activity. This change in approach has increased the difficulty of oceanographic laboratories in finding sufficiently qualified staff and providing the necessary facilities. The problems to be solved call for the attention of physicists of the highest calibre, and it will be a long time before any single country can interest an adequate number of such men in marine problems. Furthermore, it is becoming increasingly expensive to build, equip and operate a marine ocean-going research vessel. It is hoped that, as a result of the Conference, conclusions will be reached on the degree to which it is desirable for the Commonwealth countries to co-ordinate their oceanographic research programmes and to collaborate in solving outstanding fundamental problems.

\section{City and Guilds of London Institute}

THE growing importance of the City and Guilds of London Institute, and the part that it plays in advancing the cause of technical education, is the happy outcome of the enterprise of the Corporation and the Livery Companies of the City of London, which in this matter are acting fully in accordance with the tradition and past history of their respective organizations. In 1953 the Institute celebrated the seventy-fifth anniversary of its incorporation. Its progress during 1953 is described in the annual report, which contains an account of the successful launching of an appeal for $£ 100,000$ in order that the Institute could more readily meet increasing demands by industry and commerce. One of the outstanding events of 1953 was an unexpected rise in the number 